\title{
What to do when 3D Printers go wrong: Laboratory Experiences
}

\section{Dr. Nebojsa I Jaksic P.E., Colorado State University, Pueblo}

NEBOJSA I. JAKSIC holds the Dipl. Ing. degree in electrical engineering from Belgrade University, the M.S. in electrical engineering, the M.S. in industrial engineering, and the Ph.D. in industrial engineering from the Ohio State University. He is currently a Professor at Colorado State University-Pueblo. Dr. Jaksic served as the ASEE Rocky Mountain Section Chair (2007-2008), the ASEE DELOS Program Chair (2008), the ASEE DELOS Division Chair (2009), the ASEE Zone IV Conference Program Chair (2010), the ASEE Zone IV Chair (2012-2014), and as a member of the ASEE Board of Directors (20122014). Dr. Jaksic's interests include robotics, automation, and nanotechnology engineering education and research. 


\title{
What to do when 3D Printers go wrong: Laboratory Experiences
}

\begin{abstract}
The 3D-printing revolution is in full swing due to the expiration of a number of pivotal patents causing a proliferation of inexpensive 3D printers. While the 3D printer manufacturers' demonstration objects usually print well, student-designed objects do not, thus causing delays in student projects. This work describes 3D-printing laboratory experiences with unsuccessful prints (based on over 3000 print hours) in an undergraduate engineering 3D-printing lab using inexpensive 3D printers implementing fused deposition modeling (FDM) technology. Unsuccessful prints caused by 3D printer failures and by 3D-printing process failures are classified based on severity (catastrophic, compete, and partial failure types), analyzed, and corrected. The solutions include reprinting the failed objects using different object orientations, changing the printing material, changing the printing platform surface properties, rework by using tools like 3D pens, soldering irons, acetone treatment, etc. Student evaluations show that students understand and accept 3D-printing technology with its capabilities, potentials, and limitations. When dealing with partial failures and time limits, students prefer to correct small defects in complex objects and to reprint simple objects.
\end{abstract}

\section{Introduction}

The value of experiential learning through laboratory exercises in engineering education and practice is immense and is well established through the Kolb's experiential learning cycle theory $^{1-3}$ where active experimentation occupies a prominent role ${ }^{4-7}$. Physical models and prototypes are integral parts of the engineering design process and are also well documented in engineering texts ${ }^{8,9}$ and engineering education literature ${ }^{10-12}$. $3 \mathrm{D}$ printing is a form of rapid prototyping (additive manufacturing) based on material addition as opposed to material removal processes(subtractive manufacturing) such as computer numerically controlled (CNC) machining. 3D printers were used in some engineering programs to create physical models ${ }^{13-18}$. These 3D-printed objects were expensive due to the high costs of 3D printers and the materials used. Recently however, a number of new companies started producing inexpensive 3D printers thus enabling their wide use in engineering education ${ }^{19}$. New editions of textbooks started adding chapters on $3 \mathrm{D}$ printing and additive manufacturing ${ }^{20,21}$. Now, neither the costs of $3 \mathrm{D}$ printers nor the material costs are limiting factors in creating physical 3D objects. This enables students in engineering and engineering technology programs to print a large number of parts relatively quickly while progressing through their iterative designs.

In the popular media, it is assumed that if one can create a 3D digital model of an object using a computer, one can easily create the physical object by a simple push of a button. In general, the demonstration models provided by the 3D-printer manufacturers or the objects successfully printed in the past often print well. However, the new designs created by students in engineering design courses often fail to print successfully. The failed prints are time-consuming, wasteful, and could damage 3D printers. Also, they may discourage students from using 3D printers in the 
future. In most cases, failed prints are the result of inappropriate object orientations on the printing platform, dimensional miscalculations (usually not accounting for material shrinkage), unsuitable geometry for 3D printing, inadequate printing support structure, misaligned printing platform, and/or inadequate adherence of the first printed layer to the printing platform.

\section{Curricular Context}

The 3D-printing lab addressed in this work is described elsewhere ${ }^{19}$. The lab is used primarily by undergraduate engineering students (mechatronics and industrial engineering programs) for mechanical designs. 3D-printed objects are used in most of the engineering courses throughout the curriculum. The courses include Introduction to Engineering, Engineering Graphics, Calculus and Analytic Geometry, Problem Solving for Engineers (MatLab programming course), Materials Science and Engineering, Thermodynamics, Virtual Machine Design, Engineering of Manufacturing Processes, Quality Control and Reliability, ComputerIntegrated Manufacturing, Controls I, Controls II, Senior Design Projects, and Independent Research/Design Projects.

In education, in general, three sets of objectives can be identified: cognitive, affective (refer to attitudes and values), and skill learning ${ }^{22}$ (expertise gained by training and practice). Engineering education emphasizes cognitive and (to a lesser degree) skill learning objectives. Also, design emphasis (cognitive objective) and proficiency with 3D-printing processes (skill learning objective) are reflected in ABET General Criterion 3, Student Outcomes ${ }^{23}$ (c) "an ability to design a system, component, or process to meet desired needs within realistic constraints such as economic, environmental, social, political, ethical, health and safety, manufacturability, and sustainability" and (k) "an ability to use the techniques, skills, and modern engineering tools necessary for engineering practice." In addition, physical models that provide tactile, visual, and manipulative feedback to learners have been implemented successfully in general education for a long time.

The 3D-printing lab includes nine inexpensive 3D printers (a Replicator Z18 3D printer from MakerBot was recently added for creating larger objects) and employs two part-time student technicians. The printers use acrylonitrile butadiene styrene (ABS) or polylactic acid (PLA) $1.75 \mathrm{~mm}$ diameter filaments. In the last two years, students logged over three thousand 3D-printtime hours and produced over a thousand printed objects.

The 3D-printing lab is available for instructor-run lab exercises scheduled each semester for different courses and for out-of-class projects (students and community members can print almost anything they want) where lab technicians are available for 20 hours per week. The lab technicians' responsibilities are to make sure the printers have adequate and appropriate filaments loaded, keep track of the filament inventory, repair 3D printers, answer students' questions, help students when asked, perform regular maintenance like aligning/adjusting printing platforms or inspecting/changing Kapton tape, and install/upgrade software/firmware/hardware for the lab 3D printers.

\section{Qualitative Analysis of Unsuccessful Prints through Examples}

In this section, common failures based on students' failed prints are illustrated, classified, and analyzed. Also, some implemented solutions are provided. The failures can be divided into two major groups based on their cause: the 3D-printing process failures (3D-printing failures) 
due to errors in design, operation, part placement, material selection, etc. and the failures due to 3D printers' malfunctions (3D printer failures).

\section{D-Printing Failures}

3D-printing failures can be classified into three types based on their severity: (a) catastrophic 3D-printing failures where the 3D printers are damaged; (b) complete 3D-printing failures where the failed objects cannot be repaired, and (c) partial 3D-printing failures where the objects can be repaired by using some post-printing processes.

Sometimes, early during printing, a corner of the printed part warps up and separates from the printing platform. Since this corner is now higher than the tip of the extruder nozzle, the nozzle can push all the built layers and separate them from the platform. Figure 1 shows an example of catastrophic failure where parts of the extruder were engulfed in plastic. In this case, the 3D printer was left unattended overnight since the time predicted by the 3D-printing program to create a part was about 9 hours. As the first few layers were deposited, they separated from the printing platform and adhered to the printing nozzle of the extruder. Then, the nozzle and some portions of the extruder were encapsulated as more plastic was extruded. To remove the plastic build-up, a student used a heat gun to re-melt the plastic and release the extruder. However, in the process, a plastic extruder holder was partially melted as well and had to be replaced. Figure 1a shows the resulting plastic mass while Figure $1 \mathrm{~b}$ shows the heater element and partially removed plastic. After the repairs were made, and the printing platform was cleaned and realigned, the part printed successfully. The frequency of catastrophic failures is very low (in two years there were only two such failures recorded in the lab).

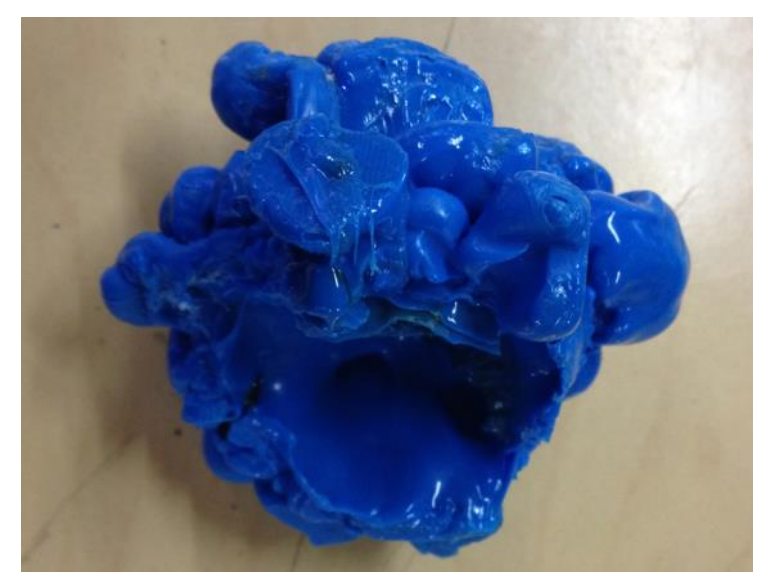

a

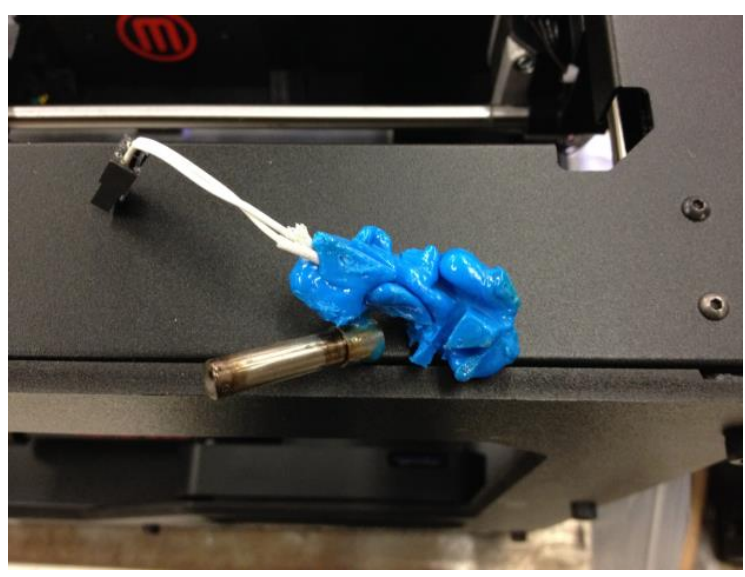

$\mathrm{b}$

Figure 1. An Example of a catastrophic 3D-printing failure: a) plastic mass formed around the extruder b) partially removed plastic from the heater element of the extruder

Two examples of complete 3D-printing failures are depicted in Figure 2. A part in Figure 2a is shown still in the $3 \mathrm{D}$ printer on the printing platform. Before printing the part, the $3 \mathrm{D}$ printer deposits plastic in a straight line and near the front edge on the printing platform to clean any plastic residue from the nozzle and to confirm that the printing platform is correctly positioned (leveled and at the correct height). Here, the 3D printer shows the well-adjusted printing platform. However, the print failed. It seems that the part started printing, but then it was 
separated from the printing platform. This is often due to the lifting of at least one edge of the part from the printing platform and then pushing the part away from its original position by the nozzle. Finally, the rest of the material was extruded in the air. Subsequently, the part was reoriented in software and printed successfully. In Figure $2 b$, part edges lifted from the printing platform during printing. The student who was printing the part decided that the deformation of the part was not acceptable and stopped the print. After the printing platform was recalibrated another unsuccessful attempt was made. Finally, the part was printed successfully on a different $3 \mathrm{D}$ printer using PLA which usually adheres better to the printing platform than ABS.

In general, large surfaces of ABS plastic deposited on the printing platform (even if the platform is heated) have a tendency to curl up. This is common with inexpensive 3D printers. Manufacturers of expensive 3D printers claim that they solved this problem by providing temperature-controlled printing environments in addition to the heated printing platforms. Manufacturers of inexpensive 3D printers use rafts, Kapton tape, paint, or paper glue to cover the surfaces of printing platforms before printing. A raft is an optional flat structure deposited between the first layer of the part and the printing platform. Rafts are designed to minimize warping and curling. They usually extend a few millimeters from the outer edges of printed objects. Rafts are elements of the object support structure, i.e. the material that helps build an object but is removed after the object is created. In this work, a reinforcement circle is added at each corner of the raft. Figure 3a shows an example of such enforced structure for a smart phone holder while Figure $3 \mathrm{~b}$ depicts a part in the 3D printer having a raft with additional circular supports. One caveat to this solution is that the removal of the raft usually leaves a rough bottom surface of the part. The surface can be sanded to a smoother finish. For ABS objects, the surface luster can be increased by brushing the surface with acetone. Acetone dissolves ABS and as acetone evaporates it leaves a high-gloss surface behind.

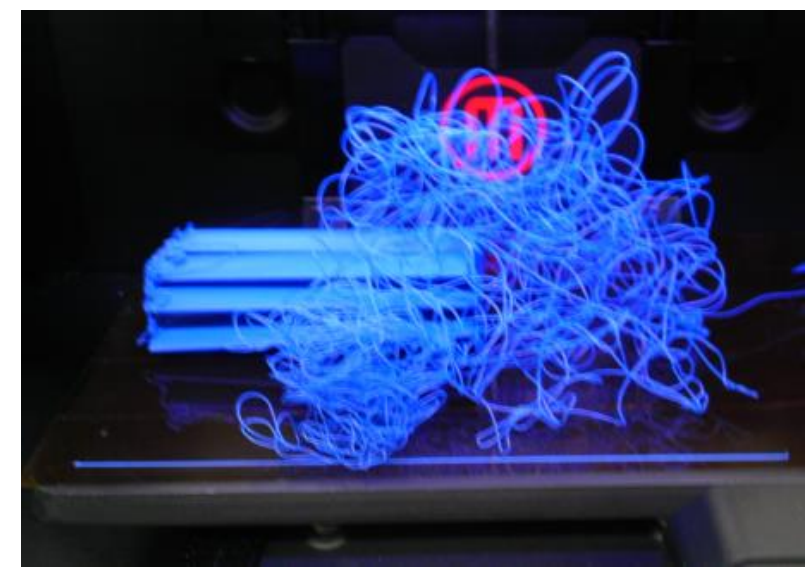

a

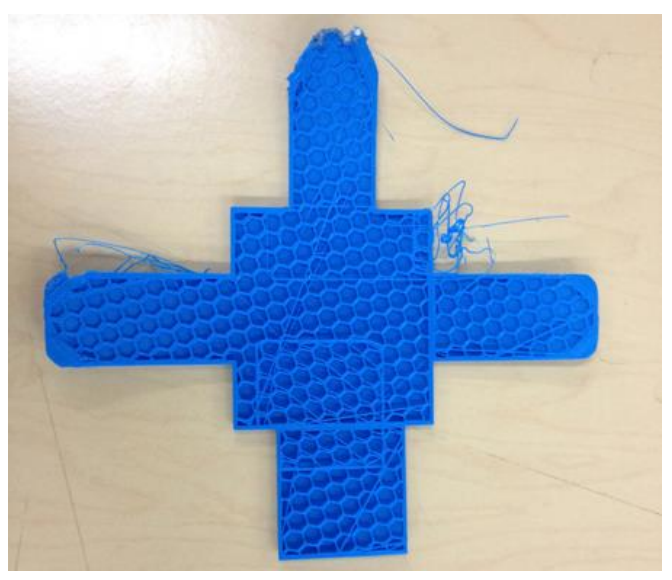

b

Figure 2. Examples of complete 3D-printing failures 


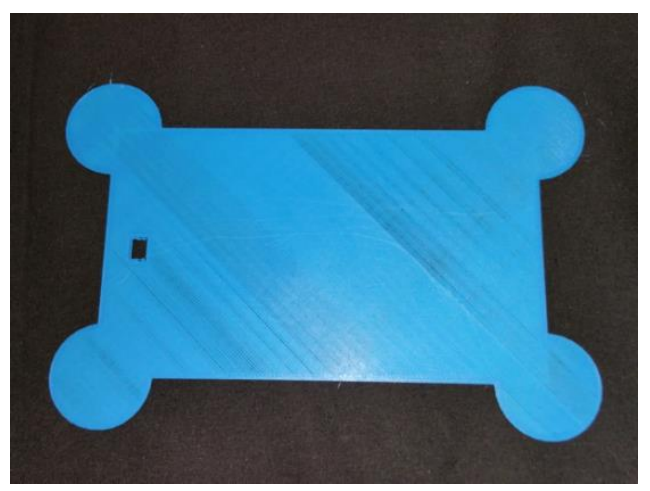

a

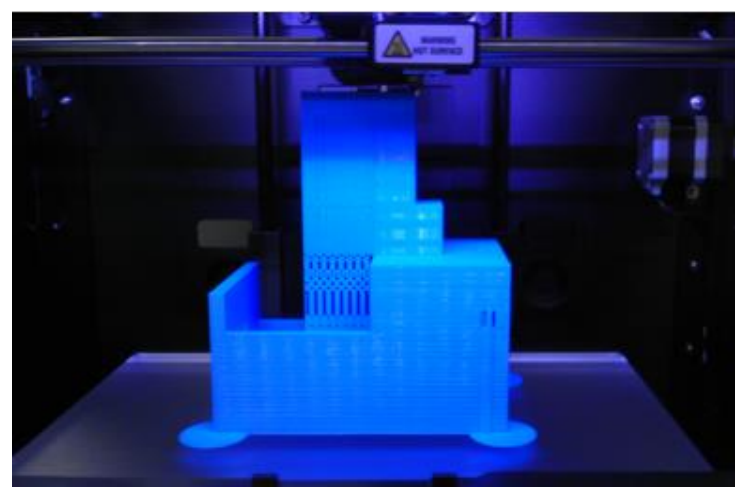

b

Figure 3. Solution to the corner curl problem by using circular raft reinforcements

Some typical examples of partial 3D-printing failures are depicted in figures 4 and 5. In Figure $4 \mathrm{a}$, an enclosure for a robotics project was printed with a flaw. Two edges of the enclosure curled up somewhat but the printer was able to recover and finish printing the object. Students working on this project tested functionality of the enclosure and since the enclosure was tall enough to clear the parts to be enclosed, the students decided to accept the part as printed. Figure $4 \mathrm{~b}$ depicts a 3D-printed figurine. The design was obtained from the Web. However, after the figurine was printed and released from the printing platform, the legs separated. There was a flaw in the design of the figurine. To reattach the legs, the student who printed the figurine used a 3D pen. This is a novel glue-gun-like hand-held device (introduced in 2014 as a successful Kickstart project) that can deposit plastic. The device uses the same ABS or PLA filament that is used in 3D printers. Figure 5 shows a portion of a Bernoulli end-effector where the connector to the shop air is not well designed dimensionally. After printing, the connector did not fit the pressurized air receptacle, so it was simply sanded down to correct dimensions. Also, the end-effector was printed with $15 \%$ infill to save time ( 8 hours for $15 \%$ infill as opposed to 17 hours for a solid build). However, this created a weak section in the part which cracked the first time it was used. To repair the crack, a soldering iron and ABS filament were used. The plastic was added to strengthen the weak section like "soldering with plastic," because at the time of the repair (2013) 3D pens did not exist.

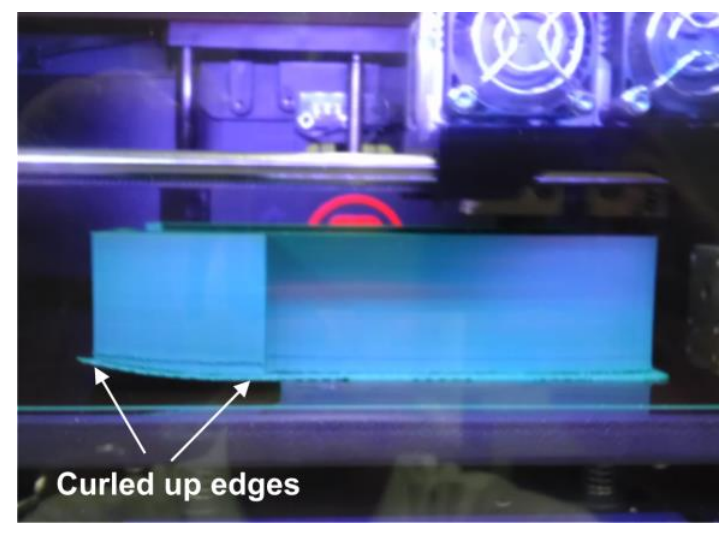

a

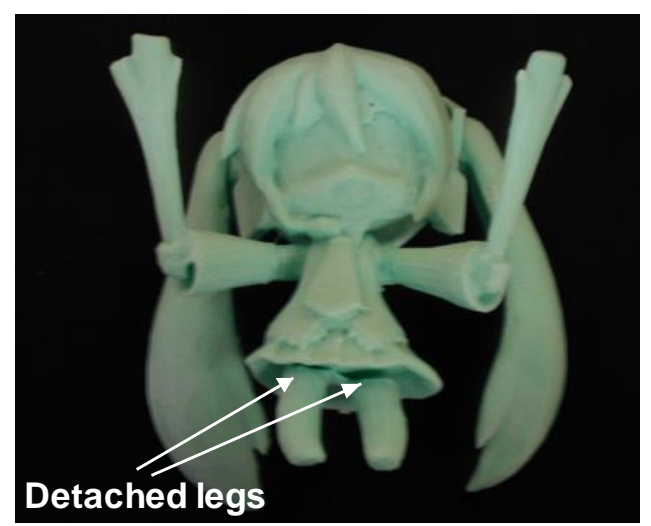

b

Figure 4. Examples of partial 3D-printing failures 


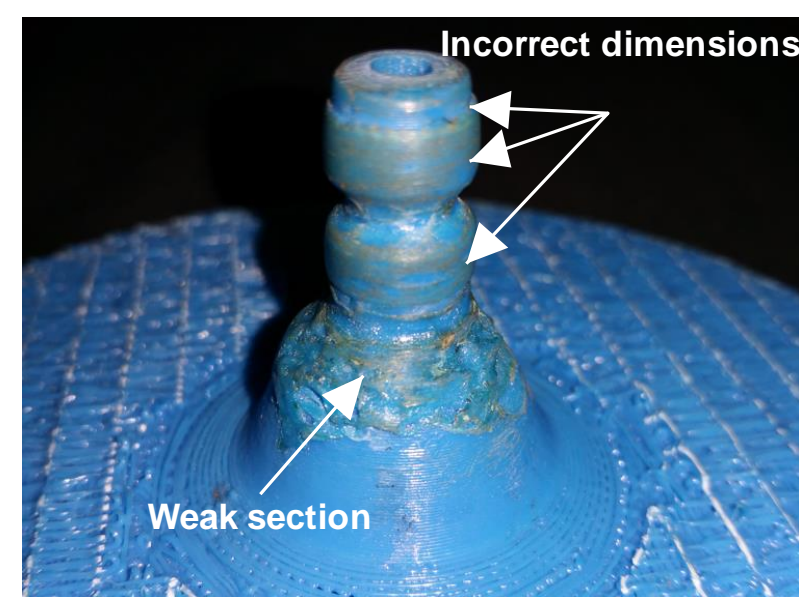

Figure 5. Partial 3D-printing failure of a robotic end-effector

\section{D-Printer Failures}

3D-printer failures are defined as failures due to malfunctioning 3D printers. If a failure requires replacement of a 3D-printer part it can be considered catastrophic. Other failures can be classified as complete (e.g., the nozzle does not extrude material during printing) or partial (e.g., a printed object surface is too coarse due to a moisture-affected filament). The technology of inexpensive 3D printers is fairly new. The inexpensive 3D printers grew out of hobby projects and have not been on the market long enough to thoroughly test. Thus, some problems dealing with 3D printers' prolonged use are not well documented or explored. One of the often encountered problems when dealing with 3D printers is the filament extrusion problem where a printer stops extruding material. Since there can be a number of reasons for this printer fault, a troubleshooting flowchart, presented in Figure 6, is developed.

The presence of filament is verified first when a nozzle fails to extrude material. Then, if filament is present, the type of filament is noted and compared to the software settings for the type of material. For example, ABS and PLA require different temperature settings to achieve optimal flow characteristics. The next step is a visual inspection of the nozzle. If the nozzle is not clogged, the filament spools are inspected for easy turning. Sometimes they need to be repositioned since the small extruder motors are not powerful enough to pull the filament when spools are hard to rotate. Special attention should be exercised when larger spools are used. To cut material costs, engineering departments may buy larger (10lb) filament spools which may cause extruder motors to stop feeding material. Possible solutions are to redistribute filament to smaller spools and use those smaller spools, to redesign extruders to include more powerful motors, or to design a better system for turning the larger spools. Figure 7 shows the last solution implemented with MakerBot 2 3D printers. A large spool is placed on 3D-printed holders with purchased metal bearings designed to minimize friction as the spool rotates. 


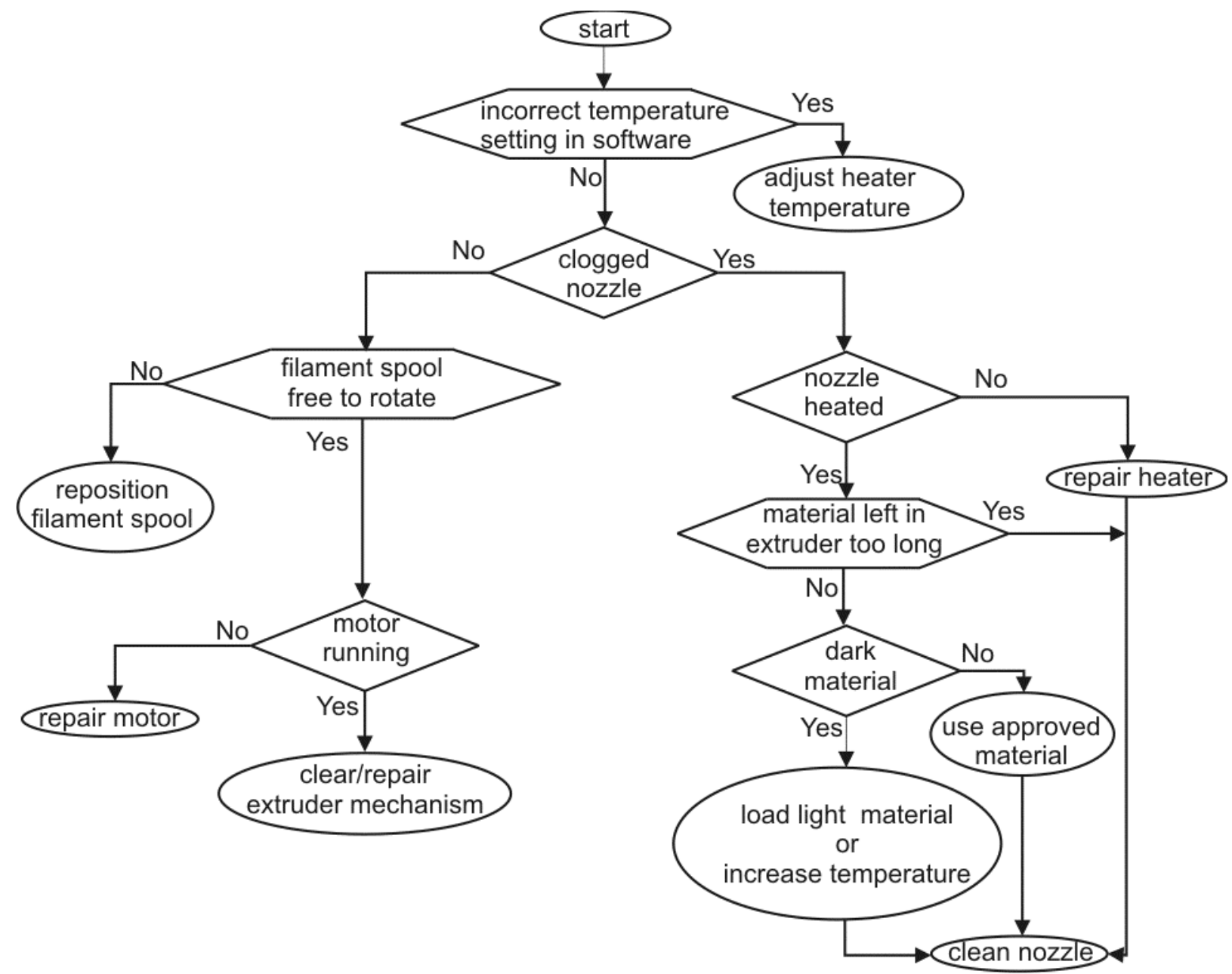

Figure 6. Troubleshooting flowchart for extruder malfunctions

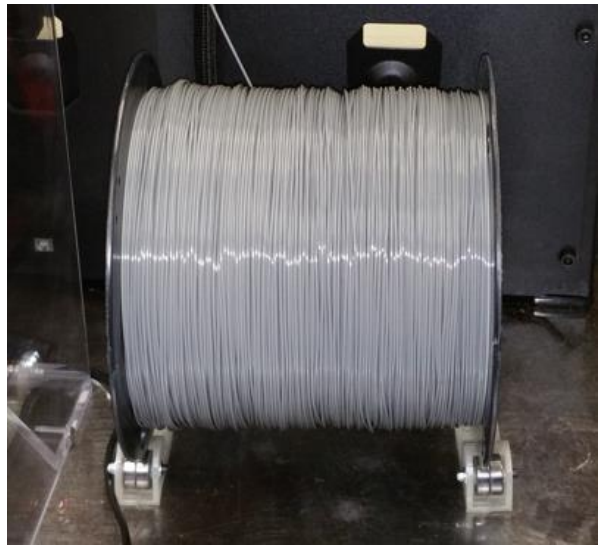

Figure 7. Large spool with 3D-printed holders and metal bearings

A trial run of the extruder motor may be required. In order to perform changes of filament spools, all 3D printers have a software function that allows extrusion of material even when there are no objects to print. When this function is executed the printer runs the extruder motor that 
uses gears to grab and feed filament. Since the extruder motor is part of a moving assembly, its wiring harness can fail due to repetitive motion and sharply bent wires. Usually, the solution is to install a wire protector that does not allow sharp bends to occur. Sometimes, when the motor is trying to feed filament, the gears that grab and feed the filament may be blocked by filament residue. Cleaning the gears usually unblocks them.

Clogged nozzles are usually the result of insufficient heating and/or material variations. If a nozzle is clogged, its temperature should be inspected first. Most 3D printers have temperature sensors and can display nozzle temperatures. Often, the heater/sensor assembly is replaced as a unit when the heater fails. Material characteristics vary significantly and can easily influence the 3D-printing process. For example, if a 3D printer was turned on and left for over 24 hours after it finished printing, it may clog the nozzle. In such a case, the filament should be unloaded, part of filament that was left in the printer cut off, and the filament loaded back again. Sometimes the nozzle has to be cleared by using a needle or using an ultrasonic cleaner. If the material is of a darker color it usually requires higher extrusion temperatures. Both ABS and PLA are subject to swelling in humid environments. Such material may cause clogging, stripping, and uneven diameter as it exits the nozzle. Storing unused filament spools in reclosable plastic bags with desiccant can alleviate humidity problems.

\section{Student Knowledge, Skills, Perceptions, and Attitudes}

To evaluate the pedagogical success of lab activities with unsuccessful 3D-printed objects, an assessment tool measuring students' knowledge and skills is developed, administered, and analyzed. A short attitude questionnaire is delivered and evaluated. Also, student perceptions and attitudes are further explored using informal interviews.

The department of engineering at our institution hosts two undergraduate engineering programs: Bachelor of Science in Engineering with specialization in Mechatronics (BSE-Mechatronics) and Industrial Engineering (IE). There are about 100 FTEs between the two undergraduate programs. All undergraduate engineering students are required to use 3D printers in many of their courses. For the purposes of this study, twelve undergraduate students of differing academic standings that attended an eight-hour student-lead workshop on 3D printing and PSoCs participated in the evaluation. A knowledge/skill-based test was administered as a pre- and post-test (before and after the workshop). This test was similar to an already published test ${ }^{19}$ (the second question of the original test was omitted). A basic attitude test was administered after the workshop. It consisted of two workshop questions asking students how interesting the 3D printing part of the workshop was and if they found it useful. In addition, individual interviews with a number of students were performed over the last two years. Interview questions revolved around usefulness of 3D printing technology, ease of use, coping with failed prints, acceptance, limitations, and suggestions for improvements.

One of the knowledge/skill-based test questions was to discuss possible causes of a failed print. The average score of the pre-test was 2.6 out of 5 and the average score of the post-test was 3.6 out of 5. Two students decided not to answer this question during the post-test. On the attitude test all students agreed that the 3D-printing portion of the workshop was interesting (average 4.9 on the 5 point Likert scale where 5 indicates "strongly agree") and useful (average 5.0 on the 5 point Likert scale). 
Interviews with students revealed that they are excited about 3D-printing technology. They appreciated time savings when working on their designs. Students found that 3D printing is not much of a stretch from what they already knew. When asked about their failed prints and their solutions there was a wide range of answers. Early in their projects most students would not repair even difficult to print objects, they would reposition them, clean the surface of the printing platform, re-level the platform and try again. In the later stages of their projects with deadlines approaching, they would correct small defects on complex objects and they would reprint simple objects after repositioning them. Only a few students were willing to spend time to increase the luster of their designs. As possible improvements, students wished they could 3D-print metal parts, be able to use 3D scanners, and be able to recycle failed prints and support material.

As a result of student and faculty experiences with inexpensive 3D printers in undergraduate engineering labs, review of pertinent literature, and student feedback, the engineering department at our institution supported a purchase of one inexpensive 3D scanner and a small plastic shredder (for 3D-printing sustainability studies). Also, a suggestion for improving our two undergraduate engineering programs by adding an additional credit-hour to the Engineering Graphics course in order to accommodate 3D-printing topics and labs is under consideration. However, 3D printing of metal parts was deemed financially unfeasible, especially since the department supports a small foundry where engineering students can use their 3D-printed patterns to create metal castings.

\section{Summary and Conclusions}

This work addressed 3D-print failures encountered in an undergraduate engineering 3D-printing lab using inexpensive 3D printers. First, the failures were classified into two groups based on the failure cause: the process or the device. They were also classified into three types based on their severity: catastrophic failures, complete failures, and partial failures. Each failure type was illustrated by at least one example and an implemented solution. Extruder failures were analyzed by implementing a troubleshooting flowchart. Student knowledge, skills, perceptions, and attitudes dealing with $3 \mathrm{D}$ printing and $3 \mathrm{D}$ printing failures were assessed. They confirmed that students were excited about 3D-printing technology, understood the technology's capabilities and limitations, and were able to cope with print failures. In general, since the cost of objects was not a limitation, students preferred to reprint failed parts rather than repair them if they didn't have time restrictions.

\section{Acknowledgment}

The author gratefully acknowledges Ryan Van Deest for his contribution to lab developments, implementations, and valued suggestions.

\section{Bibliography}

1. Kolb, D. A., Experiential Learning: Experience as the Source of Learning and Development, Prentice Hall, Englewood Cliffs, N.J., 1984. 
2. Harb, J. N., Durrant, S. O., and Terry, R. E., "Use of the Kolb Learning Cycle and the 4MAT System in Engineering Education," Journal of Engineering Education, Vol. 82, April 1993, pp. 70-77.

3. Harb, J. N., Terry, R. E., Hurt, P. K., and Williamson, K. J., Teaching Through The Cycle: Application of Learning Style Theory to Engineering Education at Brigham Young University, $2^{\text {nd }}$ Edition, Brigham Young University Press, 1995.

4. Ortiz, L. E. and Bachofen, E. M., "An Experience in Teaching Structures in Aeronautical, Mechanical and Civil Engineering, Applying the Experimental Methodology," Proceedings of the 2001 American Society for Engineering Education Annual Conference \& Exposition, Session 2526.

5. Harding, T. S., Lai, H.-Y., Tuttle, B. L., and White, C. V., "Integrating Manufacturing, Design and Teamwork into a Materials and Processes Selection Course," 2002 American Society for Engineering Education Annual Conference and Exposition Proceedings, Montreal, Canada, June 17-19, 2002. Session 1526.

6. Wyrick, D. A. and Hilsen, L., "Using Kolb's Cycle to Round Out Learning," 2002 American Society for Engineering Education Annual Conference and Exposition Proceedings, Montreal, Canada, June 17-19, 2002. Session 2739.

7. Abdulwahed, M. and Nagy, Z. K., Applying Kolb's Experiential Learning Cycle for Laboratory Education, Journal of Engineering Education, July 2009, pp. 283-294.

8. Ullman, D., The Mechanical Design Process, $4^{\text {th }}$ edition, McGraw-Hill, 2009.

9. Dieter, G. and Schmidt, L., Engineering Design, $5^{\text {th }}$ edition, McGraw-Hill, 2012.

10. Schmucker, D. G., "Models, Models, Models: the Use of Physical Models to Enhance the Structural Engineering Experience," 1998 American Society for Engineering Education Annual Conference and Exposition Proceedings, Seattle, WA, June 28-July 1, 1998. Session 3615

11. Viswanathan, V. K. and Linsey, J. S., "Build to Learn: Effective Strategies to Train Tomorrow's Designers," 2012 American Society for Engineering Education Annual Conference and Exposition Proceedings, San Antonio, TX, June 10-13, 2012. AC 2012-4896

12. Nagel, R. L., Pierrakos, O., and Nagel, J. K., "A Versatile Guide and Rubric to Scaffold and Assess Engineering Design Projects," 2013 American Society for Engineering Education Annual Conference and Exposition Proceedings, Atlanta, GA, June 22-26, 2013. Paper ID \#7298

13. Walsh, D., Griffin, L., and Crockett, R., "COSMM: An Undergraduate Laboratory for Engineering and Manufacturing Complex, Organic Shapes Using Nature as a Template," 2006 American Society for Engineering Education Annual Conference and Exposition Proceedings, Chicago, IL, June 18-21, 2006. Session 1530.

14. Lai-Yuen, S., and Herrera, M., "Integrating Real-World Medical Device Projects into Manufacturing Education," 2009 American Society for Engineering Education Annual Conference and Exposition Proceedings, Austin, TX, June 14-17 2009. Session 422.

15. Leake, J. M., "Development of an Advanced Course in Computer-Aided Design, Analysis and Prototyping," 2004 American Society for Engineering Education Annual Conference and Exposition Proceedings, Salt Lake City, UT, June 20-23, 2004. Session 2438.

16. Guidera, S., "Computer Aided Physical Models: Introducing NURBS and Fabrication in Conceptual Architectural Design Projects," 2009 American Society for Engineering Education Annual Conference and Exposition Proceedings, Austin, TX, June 14-17 2009. Session 904.

17. Garner, G. T., "Programming Printers Printed by 3D Printers," 2013 American Society for Engineering Education Annual Conference and Exposition Proceedings, Atlanta, GA, June 23-26 2013. Session 7895.

18. Chiou, R., Carr, E., Kizirian, R., Yang, Y., Killen, B., and Kwon, Y., “Application of Rapid Prototyping for Design of a Walking Robot," 2010 American Society for Engineering Education Annual Conference and Exposition Proceedings, Louisville, KT June 20-23 2010. Session 2314.

19. Jaksic, N., "Novel Experiential Learning Practices in Engineering Education Based on Inexpensive 3D Printers," Computers in Education Journal, Vol. 5, No. 4, pp. 2-17, October-December 2014.

20. Groover, M. P., Fundamentals of Modern Manufacturing: Materials, Processes, and Systems, $5^{\text {th }}$ edition, Wiley, 2012.

21. Planchard, D. C., Engineering Design with SolidWorks 2015 and Video Instruction, SDC Publications, Mission, KS, 2015.

22. Palomba, C. A. and Banta, T. W., Assessment Essentials: Planning, Implementing, and Improving Assessment in Higher Education, Jossey-Bass Publishers, San Francisco, CA 1999.

23. Anon., Criteria for Accrediting Engineering Programs Effective for Reviews During the 2015-2016 Accreditation Cycle, ABET Engineering Accreditation Commission, 2015, Accessed on January 28, 2015. from http://www.abet.org/uploadedFiles/Accreditation/Accreditation_Step_by_Step/Accreditation_Documents/Curre nt/2015-2016/E001\%2015-16\%20EAC\%20Criteria\%2011-7-14.pdf 